\title{
Nitric Oxide-Mediated Stress Imprint in Potato as an Effect of Exposure to a Priming Agent
}

\author{
Jolanta Floryszak-Wieczorek, ${ }^{1}$ Magdalena Arasimowicz-Jelonek, ${ }^{2}$ Grzegorz Milczarek, ${ }^{3}$ Lukasz Janus, ${ }^{1}$ \\ Sylwia Pawlak-Sprada, ${ }^{2}$ Dariusz Abramowski, ${ }^{1}$ Joanna Deckert, ${ }^{2}$ and Hanna Billert ${ }^{4}$
}

\begin{abstract}
${ }^{1}$ Department of Plant Physiology, Poznan University of Life Sciences, Wołynska 35, 60-637 Poznan, Poland; ${ }^{2}$ Department of Plant Ecophysiology, Faculty of Biology, Adam Mickiewicz University, Umultowska 89, 61-614 Poznan, Poland; ${ }^{3}$ Institute of Chemistry and Technical Electrochemistry, Poznan University of Technology, Piotrowo 3, Poznan, Poland; ${ }^{4}$ Department of Experimental Anaesthesiology, the Poznan University of Medical Sciences, Sw. Marii Magdaleny 14, 60-861 Poznan, Poland
\end{abstract}

Submitted 20 February 2012. Accepted 11 July 2012.

\begin{abstract}
We investigated how potato exposed to a chemical agent could activate nitric oxide (NO)-dependent events facilitating more potent defense responses to a subsequent pathogen attack. Obtained data revealed that all applied inducers, i.e., $\beta$-aminobutyric acid (BABA), $\gamma$-aminobutyric acid (GABA), laminarin, or 2,6-dichloroisonicotinic acid (INA), were active stimuli in potentiating NO synthesis in the primed potato. It is assumed, for the mechanism proposed in this paper, that priming involves reversible $S$-nitrosylated protein ( $S$-nitrosothiols [SNO]) storage as one of the short-term stress imprint components, apart from epigenetic changes sensitized by NO. Based on BABA- and GABA-induced events, it should be stated that a rise in NO generation and coding the NO message in SNO storage at a relatively low threshold together with histone H2B upregulation might create short-term imprint activation, facilitating acquisition of a competence to react faster after challenge inoculation. Laminarin elicited strong NO upregulation with an enhanced SNO pool-altered biochemical imprint in the form of less effective local recall, nevertheless being fully protective in distal responses against $P$. infestans. In turn, INA showed the most intensified NO generation and abundant formation of SNO, both after the inducer treatment and challenge inoculation abolishing potato resistance against the pathogen. Our results indicate, for the first time, that a precise control of synthesized NO in cooperation with reversible SNO storage and epigenetic modifications might play an important role in integrating and coordinating defense potato responses in the priming phenomenon.
\end{abstract}

The phenomenon of priming in plants has been well-known and is widely accepted as a unique state of an enhanced capacity to mobilize faster and more potent defense responses to a subsequent abiotic or biotic stress. Such an amplified response to secondary abiotic stress is known as the hardening or acclimation process; in turn, a more efficient defense response to pathogens is usually described as an effect of priming or plant sensitization (Prime-A-Plant Group 2006). The primed mobilization of defense is often associated with the development of

Corresponding author: J. Floryszak-Wieczorek; Fax: +48-61-848-71-79; E-mail: florysza@jay.up.poznan.pl

* The $\boldsymbol{e}$-Xtra logo stands for "electronic extra" and indicates that four supplementary figures are published online. local immunity or activation of a long-lasting systemic acquired resistance (SAR) response. Priming follows perception and recognition of pathogen- or microbe-associated molecular patterns and some compounds elicited by pathogens; however, sensitization may also be induced by treatment with various chemical agents.

Although clear evidence for systemic plant immunity has been provided by Chester (1933) and subsequent generations of scientists (Hammerschmidt 1999; Kuć 1982; Ross 1961; Ryals et al. 1996; van Loon 1997) the molecular basis of induced resistance is still poorly recognized. Much still remains to be understood about the mechanism by which plants might generate biochemical or genetic modifications to potentiate resistance to future stress exposure. The existence of a stress imprint in the primed plant to store information on a previous stress if the next one comes was proposed by Bruce and associates (2007). Priming as an enhanced capacity to acquire defense competence involves the accumulation of dormant mitogen-activated protein kinases (MPK), chromatine modifications, and alternations of primary metabolism (Conrath 2011). For the establishment of the alert state, it seems to be pivotal to gain and maintain an efficient pattern of gene expression that has been prepared earlier. Thus one hypothesis of priming proposed that chromatine modifications such as DNA and histone methylation, acetylation, ubiquitination, and poly-ADP-ribosylation (Zhang 2008) sensitize defense genes for future rapid upregulation (Van den Burg et al. 2009). Another proposition is that cell sensitization involves the accumulation of signaling proteins and transcription factors in an inactive configuration that are activated upon exposure to stress (Bruce et al. 2007; Conrath 2011).

Among endogenous signals, which potentially modulate defense responses in acquired resistance, a special role is played by nitric oxide (NO). NO is an important chemical messenger with diverse physiological functions in plants. Evidence that $\mathrm{NO}$ is involved in signaling defense responses during plantpathogen interactions has been well-documented in numerous experiments during the last two decades (Arasimowicz and Floryszak-Wieczorek 2007; Baudouin 2010; Delledonne et al. 1998; Durner et al. 1998; Moreau et al. 2010; Wendehenne et al. 2004). Early NO overproduction, known as a NO burst generated by the plant attacked by a pathogen seems to be closely dependent on the genetic makeup of the plant and the pathogen (Yoshioka et al. 2009; Zeier et al. 2004). A majority of all NOaffected proteins seem to be regulated by $S$-nitrosylation, which occurs by the transfer of NO moiety to thiol groups of cysteine residues. For a regulatory mechanism, the reversibil- 
ity of this modification is a very important feature (Benhar et al. 2009; Lindermayr et al. 2010; Spadaro et al. 2010). A reversible process of protein nitrosylation through NO and denitrosylation may serve similar functions in the signal transduction pathway as the mechanism of phosphorylation and dephosphorylation (Abat et al. 2008). Recently, it has been established that dormant MPK are accumulated during Arabidopsis plant priming by treatment with a SAR activator such as benzothiadiazole (BTH) (Beckers et al. 2009). MPK activity is induced upon phosphorylation by MPK kinases (i.e., MPKK or MEK). Priming by treatment with BTH as the synthetic analog of salicylic acid resulted in an accumulation of mRNA and inactive proteins of MPK3 and MPK6. Both enzymes have been documented to play an important role in defense responses of Arabidopsis to stress factors (Nakagami et al. 2005; Ren et al. 2008). Moreover, enhanced levels of MPK3 and MPK6 linked to upregulation of $P A L 1$ and $P R 1$ gene expression were detected in upper leaves of Arabidopsis after priming of lower leaves followed by the inoculated plant being challenged with Pseudomonas syringae pv. tomato (Beckers et al. 2009). These data emphasize the fact that inactive accumulation of signaling enzymes MPK3 and MPK6 is a critical step in priming Arabidopsis for defense.

According to the proposed concept of Bruce and associates (2007) and Conrath (2011) in the state of enhanced alertness, an induced accumulation of inactivated signaling proteins and key transcription factors takes place, which might be hyperactivated in response to the challenge inoculation. The present state of knowledge is insufficient to fully answer the question concerning the manner in which information on cell sensitizing is encoded and stored.

The study presented here was undertaken to clarify whether NO is generated and involved in the priming state of potato. In order to solve this problem, we investigated NO-mediated events triggered by four well-known inducers of acquired resistance, i.e., $\beta$-aminobutyric acid (BABA), $\gamma$-aminobutyric acid (GABA), laminarin (the linear $\beta$-1,3-glucan), and 2,6-dichloroisonicotinic acid (INA).

BABA, a nonprotein amino acid rarely found in nature, has been known for around 50 years (Papavizas 1964; Papavizas and Davey 1963). BABA has a high potential as a priming agent and displays a broad spectrum of activity against many disease and

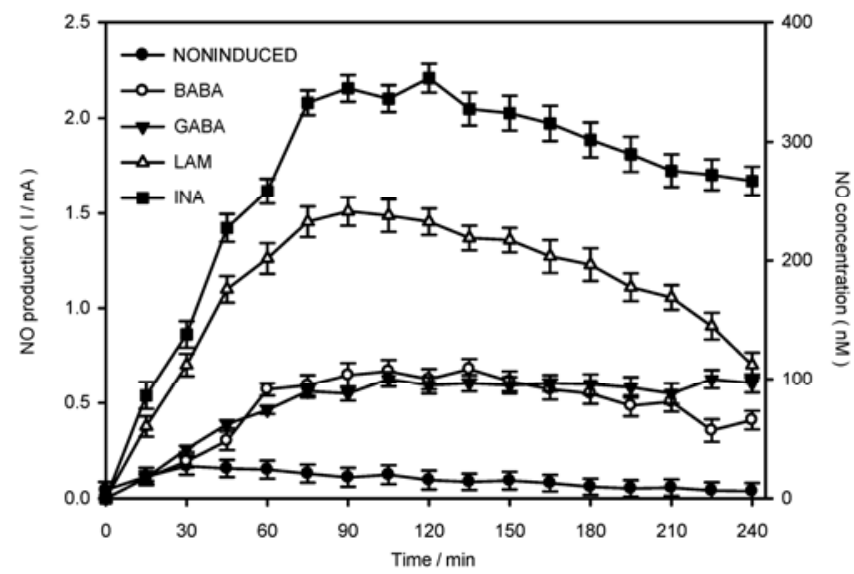

Fig. 1. Nitric oxide (NO) generation in leaves of potato cv. Bintje treated with water or, individually, with $2 \mathrm{mM} \beta$-aminobutyric acid (BABA), $2 \mathrm{mM}$ $\gamma$-aminobutyric acid (GABA), laminarin (LAM) at $90 \mathrm{mg} / \mathrm{liter}$, or 0.15 $\mathrm{mM}$ 2,6-dichloroisonicotinic acid (INA). Intracellular NO production was monitored using a NO selective needle-type electrode $(20 \mu \mathrm{m})$. Changes of NO peak current were recorded in the leaf tissue as a function of time after inducer treatment. Values represent the average of data \pm standard deviation of three independent experiments. abiotic stress factors (Cohen and Gisi 1994; Conrath 2009; Jakab et al. 2001, 2005; Zimmerli et al. 2008). The mechanism of BABA-induced resistance involves an accumulation of pathogenesis-related (PR) proteins (Jakab et al. 2001), abscissic aciddependent callose deposition (Ton and Mauch-Mani 2004), and jasmonic acid-dependent upregulation of phenylpropanoidderived phenolic compounds (Hamiduzzaman et al. 2005). Different data and signaling pathways engaged in BABA priming effects probably depend on the plant-pathogen system, BABA concentrations used, and the method of BABA application.

GABA, a less potent inducer than BABA (Cohen et al. 1999), is known as a neurotransmitter in animals, but it has been documented in plants as well (Shelp et al. 1999). GABA is not phytotoxic, even at high doses, probably because it is rapidly metabolized in plants (Cohen and Gisi 1994).

Laminarin is a linear $\beta$-1,3-glucan derived from the brown algae Laminaria digitata; it protects plants, probably by mimicking carbohydrate compounds derived from fungal cell walls or elicitors secreted by other microorganisms. Laminarin elicited defense-related signaling events and an accumulation of PR proteins in tobacco in its defense against bacteria (Klarzynski et al. 2000) and in grapevine against Botrytis cinerea and Plasmopara viticola (Azis et al. 2003).

INA, the functional analog of salicylic acid, has been shown to induce defense responses and SAR against bacterial and fungal diseases (Kauss et al. 1992; Kessmann et al. 1994). INA is closely associated with the transcriptional activation of genes encoding PR proteins (van Loon 1997) by a redox-dependent conformational switch of NPR1 (Mou et al. 2003). In contrast to BTH or salicylic acid, INA is insufficiently tolerated by most crops, which limits the practical use of this inducer (Ryals et al. 1996).

In our study, we have recognized how the potato plant exposed to the above-mentioned chemical agents could activate NO-dependent events, facilitating more potent defense responses to a subsequent pathogen attack. To this end, we tested the ability of particular inducers to cause NO production linked with $H 2 B$ gene expression and concentration of $S$-nitrosothiols (SNO) after the induction and challenge inoculation with $P$. infestans.

\section{RESULTS}

\section{SAR inducers caused NO production.}

Individual inducers were tested in terms of their ability to mediate changes in NO production soon after chemical treatment (Fig. 1). All the inducers used were effective in NO elicitation, and the kinetics, unlike the intensities of NO generation, were very similar within the time frame of the experiment. INA induced a rapid increase in NO synthesis, which reached a maximum between 75 and 120 min of treatment corresponding to more than 2 nanoamperes (nA) (approximately $0.33 \mu \mathrm{M}$ of $\mathrm{NO}$ concentration) and remained at a relatively high level. Also, laminarin elicited rapid changes in NO production, beginning to increase at $15 \mathrm{~min}$, peaking at $1.4 \mathrm{nA}$ (approximately $0.22 \mu \mathrm{M}$ of NO concentration) at $90 \mathrm{~min}$, and then decreasing slowly. The application of GABA and BABA led to NO generation that reached, respectively, $0.7 \mathrm{nA}$ (approximately $0.1 \mu \mathrm{M}$ of $\mathrm{NO}$ concentration) and $0.6 \mathrm{nA}$ (approximately $0.08 \mu \mathrm{M}$ of $\mathrm{NO}$ concentration) between 75 and 120 min of treatment. It needs to be added here that NO production induced by INA was three times greater than the BABA-induced one. Moreover, NO formation triggered after INA, laminarin, GABA, and BABA treatments did not return to the background level and was consequently higher than in the control at $4 \mathrm{~h}$ (Fig. 1). In the control noninduced potato leaves, NO production was low and quasi-linear within $4 \mathrm{~h}$, probably due to a constitutive $\mathrm{NO}$ production or 
tissue microwounding as a consequence of the needle-type electrode being inserted in potato leaves (Arasimowicz et al. 2009). Moreover, the application of NO inhibitors has not shown the main enzymatic source of NO synthesis in potato leaves (Supplementary Fig. 1).

\section{$H 2 B$ histone gene expression}

in inducer-treated potato leaves.

The expression of the $H 2 B$ histone gene elicited by an inducer, i.e., BABA, GABA, laminarin, or INA, was analyzed by reverse transcription polymerase chain reaction (RT-PCR). The
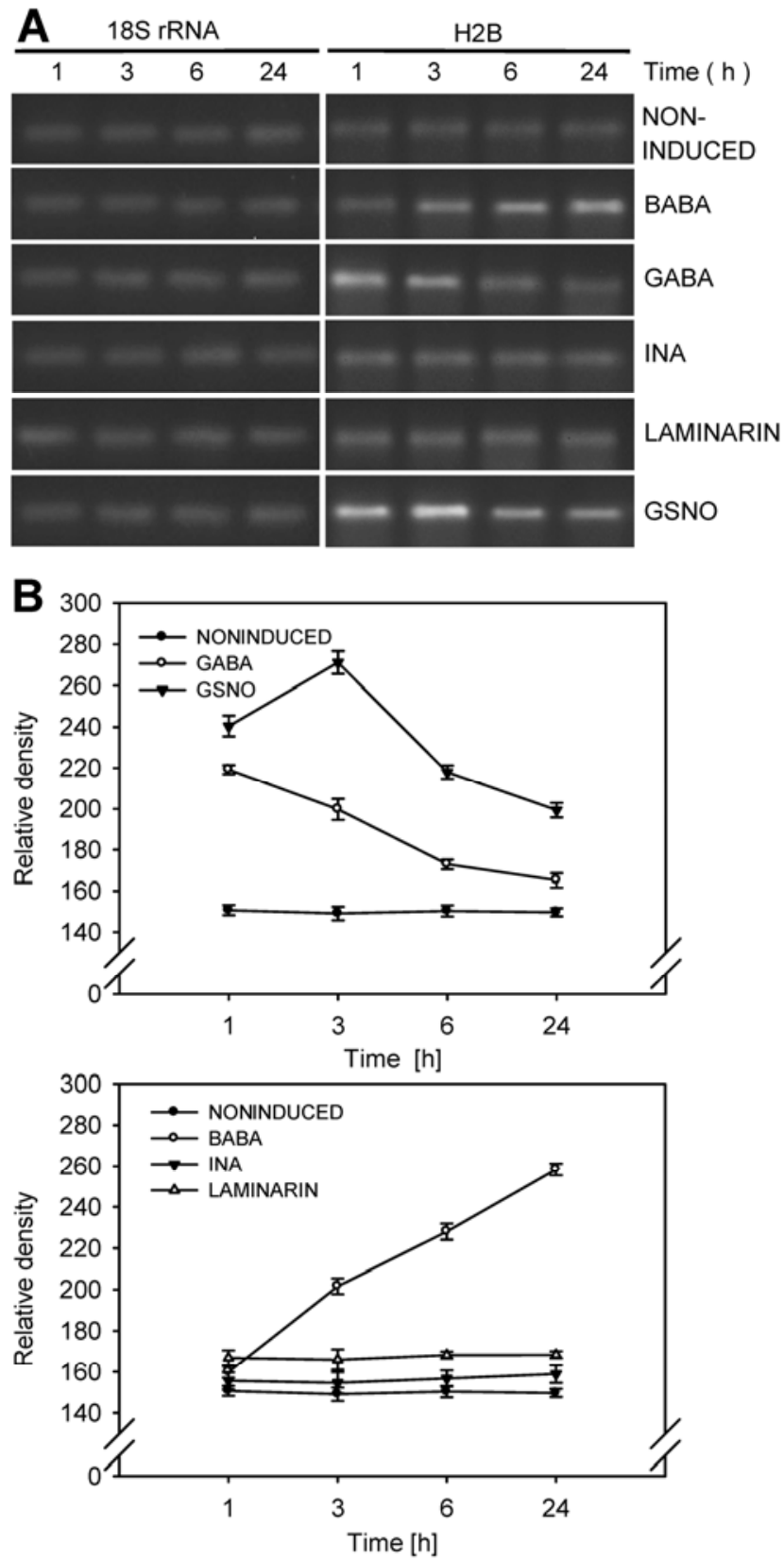

Fig. 2. Time course of the expression of histone H2B mRNA in leaves of potato $\mathrm{cv}$. Bintje treated with water or, individually, with $2 \mathrm{mM} \beta$-aminobutyric acid (BABA), $2 \mathrm{mM} \gamma$-aminobutyric acid (GABA), laminarin at 90 $\mathrm{mg} /$ liter, or $0.15 \mathrm{mM}$ 2,6-dichloroisonicotinic acid (INA) at 1, 3, 6, and $24 \mathrm{~h}$ after the application. The $18 S$ rRNA gene with a constitutive level of expression was used as the internal standard. A, Products were separated on $2 \%$ agarose gels stained with ethidium bromide, and $\mathbf{B}$, quantified by densitometry. Intensities of individual bands were compared with the internal standard as a point of reference $(100 \%)$. Values represent the average of data \pm standard deviation of three independent experiments.
18S rRNA gene with a constitutive level of expression was used as the internal standard (Fig. 2A and B). In potato leaves treated with BABA, the histone $H 2 B$ gene was systematically up-regulated. The steady state levels of mRNA for $\mathrm{H} 2 \mathrm{~B}$ increased at $1 \mathrm{~h}$ after BABA had been supplied, and after 3,6 , and $24 \mathrm{~h}$ of treatment, it was respectively 33, 50, and $70 \%$ higher than in the control. GABA elicited the rise of H2B histone transcript accumulation (a $33 \%$ increase) after $1 \mathrm{~h}$ of treatment, and thereafter, it slowly declined. The application of INA and laminarin did not change the constant level of mRNA accumulation of the $H 2 B$ histone gene, being slightly higher than in the control after laminarin treatment.

The analyses have also been focused on the effect of $S$-nitrosoglutathione reductase (GSNO) (as a NO donor) on the $H 2 B$ histone gene expression in potato leaves. The NO-mediated mRNA transcript for $\mathrm{H} 2 \mathrm{~B}$ histone was rapidly up-regulated (an $80 \%$ increase) at $3 \mathrm{~h}$ after the NO donor had been supplied, and thereafter, it decreased slowly.

\section{Induced production of total SNO.}

The total pool of SNO was determined by a precise chemiluminescence method (details below) in the lower potato
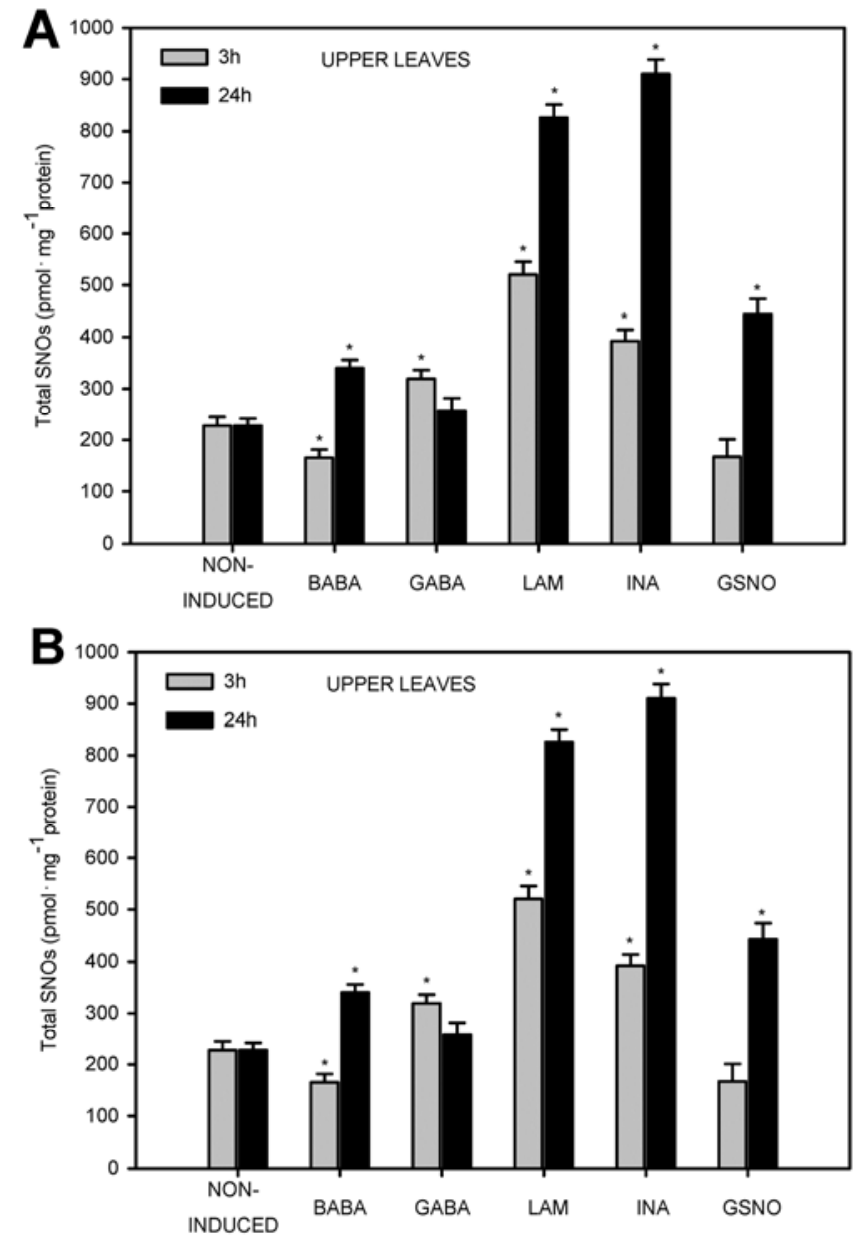

Fig. 3. Total contents of $S$-nitrosothiols (SNO) in leaves of potato cv. Bintje treated with water or $200 \mu \mathrm{M} S$-nitrosoglutathione reductase (GSNO) or, individually, with $2 \mathrm{mM} \beta$-aminobutyric acid (BABA), $2 \mathrm{mM} \gamma$-aminobutyric acid (GABA), laminarin (LAM) at $90 \mathrm{mg} / \mathrm{liter}$, or $0.15 \mathrm{mM} \mathrm{2,6-}$ dichloroisonicotinic acid (INA) at 3 and $24 \mathrm{~h}$ after the application. SNO content was determined by chemiluminescence, using a Sievers Nitric Oxide Analyzer NOA280i. A, Lower treated leaves and B, upper leaves of induced plant. Values represent the average of data \pm standard deviation of three independent experiments. ${ }^{*}=$ significantly different from the noninduced at $P<0.005$. 
leaves treated with an inducer and in the upper, untreated leaves of the same induced plant at 3 and $24 \mathrm{~h}$ after the application of either BABA, GABA, laminarin, or INA, respectively (Fig. 3A and B). In the lower leaves of BABA-treated plants, the amount of SNO was close to that in the control at $3 \mathrm{~h}$, and it then increased twofold at $24 \mathrm{~h}$. Similar variations were recorded in the upper leaves of BABA-treated plants. The GABA inducer, known as a neurotransmitter in animals, caused a twofold rise in SNO accumulation at $3 \mathrm{~h}$, which then rapidly decreased at $24 \mathrm{~h}$ after treatment, both in lower and upper leaves. In laminarin-pretreated leaves, a threefold greater SNO production was observed at $3 \mathrm{~h}$, and thereafter, the SNO level strongly increased at $24 \mathrm{~h}$, especially in the upper leaves. In turn, the next inducer, INA, induced a 3.5-fold growth in SNO levels at $3 \mathrm{~h}$, and at $24 \mathrm{~h}$, it reached more than a fivefold augmentation of the SNO pool in the lower and upper leaves when compared with the control ones.

\section{SNO contents in plants treated with GSNO.}

The concentration of SNO was calculated in the lower leaves treated with $200 \mu \mathrm{M}$ GSNO and the upper ones of the same potato plants at 3 and $24 \mathrm{~h}$ after NO donor application.
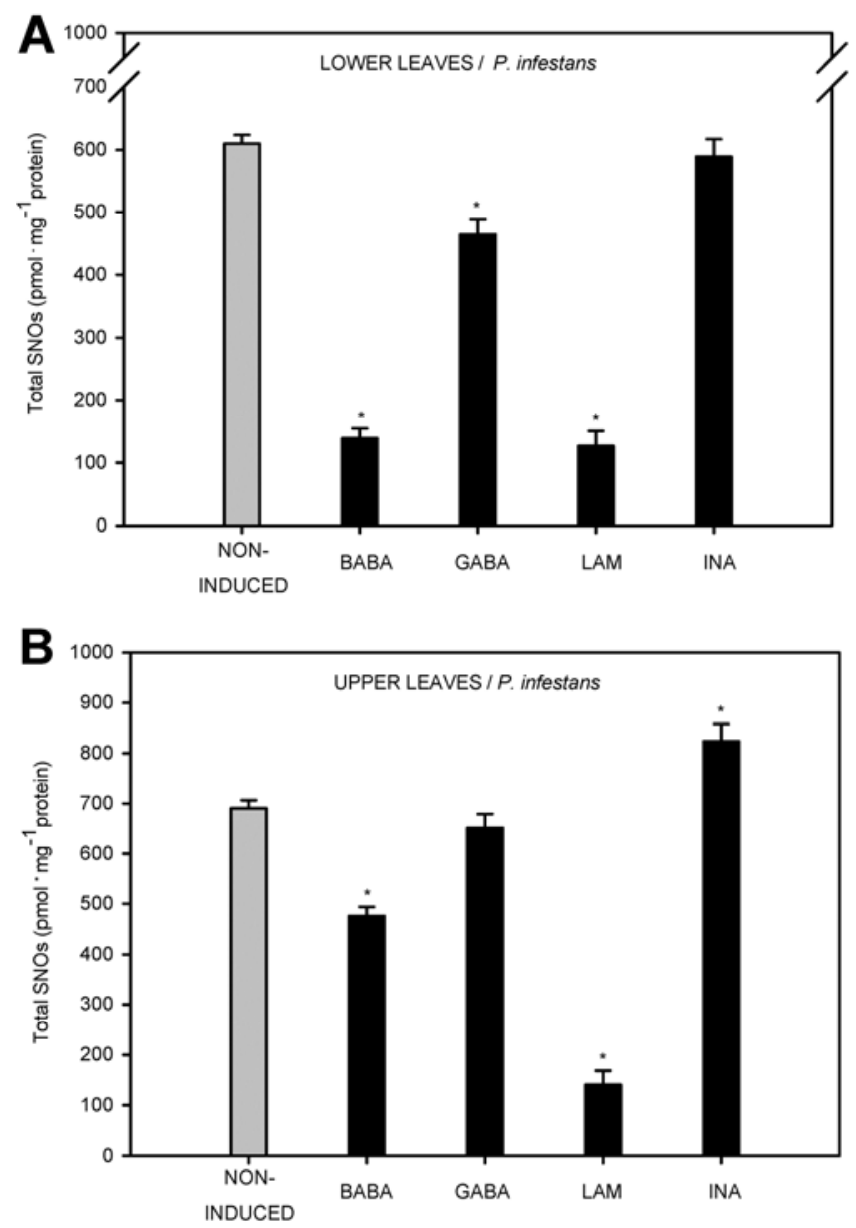

Fig. 4. Total content of $S$-nitrosothiols (SNO) in leaves of a susceptible potato $\mathrm{cv}$. Bintje treated with water or, individually, with $2 \mathrm{mM} \beta$-aminobutyric acid (BABA), $2 \mathrm{mM} \gamma$-aminobutyric acid (GABA), laminarin (LAM) at $90 \mathrm{mg} /$ liter, or $0.15 \mathrm{mM}$ 2,6-dichloroisonicotinic acid (INA) and, then, challenge-inoculated with Phytophthora infestans. Whole potato plants were inoculated at $72 \mathrm{~h}$ after the local inducer application. SNO content was determined by chemiluminescence, using a Sievers Nitric Oxide Analyzer NOA280i, at $24 \mathrm{~h}$ after inoculation. A, Lower leaves pretreated with inducer and $\mathbf{B}$, upper leaves of immunized plant.Values represent the average of data \pm standard deviation of three independent experiments. $*=$ significantly different from the noninduced at $P<0.005$.
The GSNO treatment did not increase the endogenous pool of SNO in potato plants at $3 \mathrm{~h}$ (Fig. $3 \mathrm{~A}$ and B). A strong SNO production with an approximately tenfold increase in the treated leaves and 2.5-fold increase in the leaves above was observed only at $24 \mathrm{~h}$.

\section{Total SNO levels after the challenge inoculation.}

Three days after the local leaves were induced with BABA, GABA, laminarin, or INA, the whole potato plants were inoculated with Phytophthora infestans and the total pool of SNO was analyzed in the lower and the upper leaves at $24 \mathrm{~h}$ after the challenge inoculation. In the control (noninduced) plant, the pathogen was able to trigger an early increase in SNO concentrations (two- and threefold higher) both in the lower and upper leaves as compared with the healthy potato plants (Fig. 4A and B). In turn, BABA-, GABA-, and laminarin-treated plants showed significantly lower levels of SNO accumulation in the whole plants after inoculation. The total pool of SNO increased only slightly in INA-supplied and then inoculated potato leaves as well as when compared with noninduced and inoculated leaves.

\section{The index of disease.}

Based on the index of disease assay, it has been found that the highest effectiveness of SAR inducers in terms of the protection of potato leaves against $P$. infestans was found for BABA and GABA, followed by laminarin, with INA being almost ineffective (Fig. 5A and B). BABA triggered high local and systemic protection, with visible disease spots smaller than $25 \%$ of the leaf area. GABA was less potent in P. infestans symptom reduction and, therefore, several late blight spots occupied more than $50 \%$ of potato leaf blades. Laminarin at the concentration used improved mainly distal protection against $P$. infestans in potato upper leaves. INA application at the concentration used produced least protective effects, and the oomycete pathogen colonized leaf tissue almost to the same degree as in noninduced potato leaves. Late blight symptoms 5 days after $P$. infestans challenge inoculation in the lower and upper leaves of immunized potato are presented in Supplementary Figure 2.

\section{DISCUSSION}

There is an increasing body of evidence that treatment of plants with certain resistance-inducing compounds may lead to the establishment of a unique state of enhanced plant alertness, known as the primed state of defense. Primed plants display both faster and usually stronger defense reactions upon a further challenge with a specific stressor. The mechanism for storing or coding information on a previous priming event indicates that primed plants possess some form of biochemical or genetic modification, referred to as "stress imprint," that generates future responses if the stress recurs (Bruce et al. 2007). Generally, the sensitization for defense can last for several days, but it has been documented that the stress imprint can sometimes be carried forward to the next generation, suggesting that plants may inherit a sensitization due to priming (Molinier et al. 2006; Slaughter et al. 2012). Therefore, research is focused on the understanding of molecular mechanisms and the genetic basis for the priming phenomenon. The main problem lies in the fact that various induced resistance mechanisms associated with an augmented capacity to mobilize an effective activation of defense responses usually become apparent after the challenge of the induced tissue (Conrath et al. 2002).

In the study presented here, we investigated how NO could mediate in the molecular mechanisms that regulate priming and subsequent potentiation of cellular defense responses in 
plant. We compared NO-dependent reactions in potato leaves that had been induced with either BABA, GABA, laminarin, or INA, in the formation of a short-term stress imprint in potato plants. Results obtained, using the electrochemical method for a precise NO measurement, revealed that all applied inducers that were well known for SAR were active stimuli in potentiating NO synthesis in induced potato plants. Almost immediately after chemical agent treatment, augmented NO production can be detected in potato leaf tissue. INA showed a more effective competence in NO synthesis than laminarin, GABA, and BABA. NO production after treatment with INA was threefold greater than in BABA-treated leaves, although the NO level in BABA-treated leaves was significantly higher when compared with noninduced leaves. Interestingly, the same kinetics and intensity of BABA-caused NO production were recorded at various concentrations, i.e., $0.2,2.0$, or $20 \mathrm{mM}$ of BABA (Supplementary Fig. 3). NO synthesis caused by particular inducers was observed very early (within minutes), with a maximum $\mathrm{NO}$ generation at around $90 \mathrm{~min}$ after treatment, and it remained enhanced until the end of the experiments.

In comparison with a previous demonstration that BABA was unable to induce NO production as monitored by 4,5-diaminofluorescein diacetate in grapevine cells (Dubreuil-Maurizi et al. 2010), these results indicate that BABA-sensitized potato cells are able to trigger early signaling events via $\mathrm{NO}$ at a relatively low level measured by a NO-selective microsensor.

It has also been reported that $P R$ gene expression was differentially regulated in BABA-treated plants. Both in grapevine cells (Dubreuil-Maurizi et al. 2010; Hamiduzzaman et al. 2005) and in Arabidopsis plants (Ton et al. 2005; Zimmerli et al. 2000), BABA by itself did not modify the expression of $P R$ genes. In turn, evidence for BABA-induced upregulation of PR-1 gene expression has been described in Arabidopsis thaliana (Slaughter et al. 2012; Van Hulten et al. 2006). The observed discrepancy in BABA priming effects is frequently ascribed to different plant species, differing concentrations of applied inducer, and various experimental approaches. Recently, using more advanced and sensitive technologies, it has been revealed that $\mathrm{BABA}$ treatment leads to an induction of $P R$ gene expression, although at a much lower level than the one noted after contact with a challenging pathogen (Slaughter et al. 2012; Zimmerli et al. 2008).

It has been stated (Conrath et al. 2002; Prime-A-Plant Group 2006) that the establishment of a short-term imprint contributes to the accumulation of signaling proteins and transcription factors in their inactive forms and their quick upregulation after a subsequent exposure to stress. It has been suggested that this metabolic state could involve protein $S$-nitrosylation and denitrosylation as an important reversible post-translational protein modification changing its activity similarly to the well-known mechanism of protein phosphorylation and dephosphorylation (Abat et al. 2008). NO as a reactive molecule is the $S$-nitrosylating agent of cysteine thiols in proteins. Because $S$-nitrosylation belongs to rapidly reversible protein modifications, the NO message might be quickly converted into a physiological response, hence, SNO are widespread signaling molecules that regulate immunity in plants (Badouin 2010). Therefore, $S$-nitrosylated or denitrosylated proteins might be potential candidates for the storage of prime information known as the stress imprint.

In this study, we concentrated on the measure of total SNO content that was quantified by a chemiluminescence method in the lower potato leaves treated with an inducer and in the upper, untreated leaves of the same induced plant. Generally, it has been shown that an increase in the total SNO pool correlated with a differentiated increase in NO production potentiated by the applied inducers. Only a slight rise in SNO accu- mulation occurred in BABA-treated leaves, with more evidence being recorded for GABA, in comparison to the strong upregulation in the cases of laminarin and INA at $24 \mathrm{~h}$, both in the lower potato leaves treated with inducer and in the upper leaves when compared with the leaves of noninduced potato plants. In the course of the analyses of GSNO application influencing SNO concentration in potato plants, it was observed that the NO donor did not affect the level of the SNO pool at $3 \mathrm{~h}$ after the leaf treatment. GSNO-dependent, drastic augmentation of SNO was visible at later hours $(24 \mathrm{~h})$ than it was for the inducers that were used.

It needs to be emphasized here that all the applied inducers increased the SNO pool by protein $S$-nitrosylation, probably making the targeted proteins temporarily downregulated. Thus, these data refer to the above statement (Bruce et al. 2007; Prime-A-Plant Group 2006) that the priming state involves an accumulation of inactive cellular proteins that play a key role in signal amplification being activated after a challenge inoculation leading to resistance. From the list of thoroughly characterized plant $S$-nitrosylated proteins, it has recently emerged
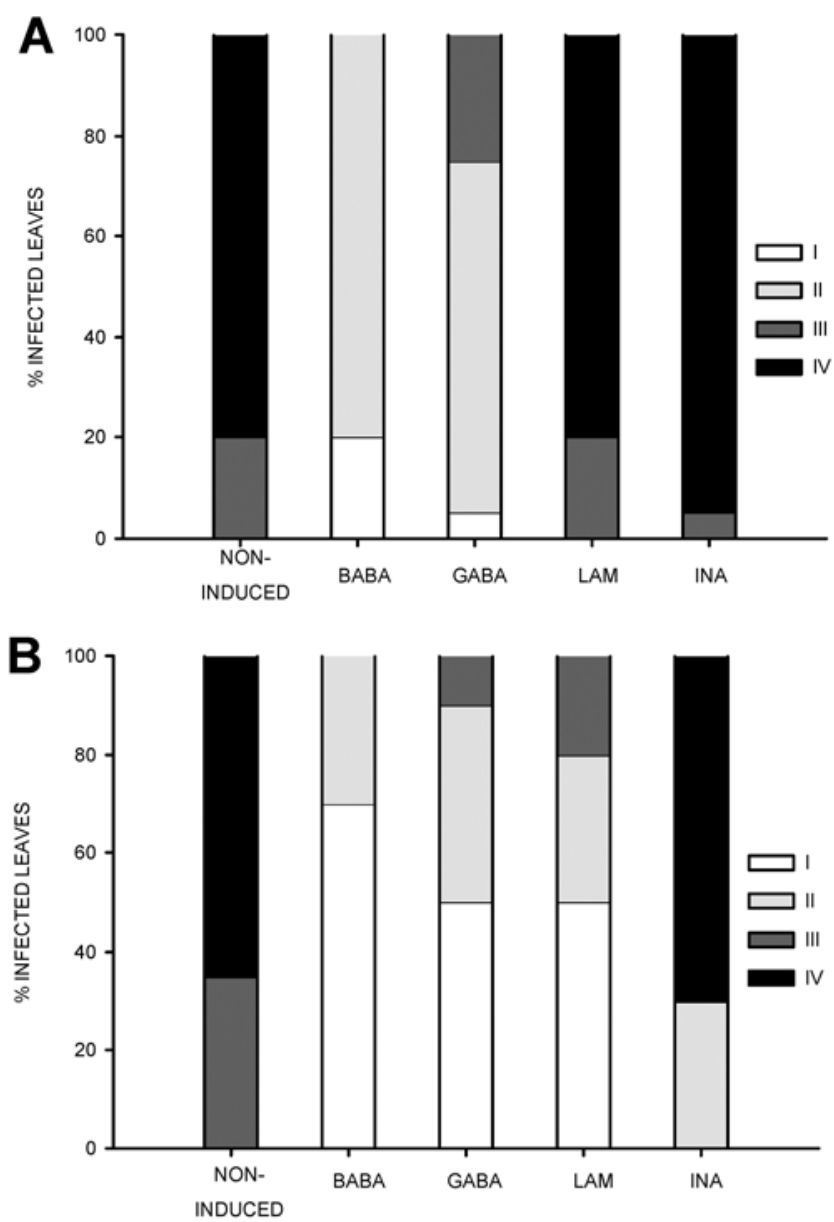

Fig. 5. Local and systemic protection of susceptible potato cv. Bintje against Phytophthora infestans. Late blight lesion development was observed A, Lower leaves treated with water or $2 \mathrm{mM} \beta$-aminobutyric acid (BABA), $2 \mathrm{mM} \gamma$-aminobutyric acid (GABA), laminarin (LAM) at 90 $\mathrm{mg} /$ liter, or $0.15 \mathrm{mM}$ 2,6-dichloroisonicotinic acid (INA). B, Upper leaves of an induced and then challenge-inoculated plant. Whole potato plants were inoculated at $72 \mathrm{~h}$ after the local inducer application. The index of disease development on potato leaves at day 5 of $P$. infestans challenge inoculation based on a 1 to 4 scale representing the percentage of leaf area covered by late blight symptoms ( $\mathrm{I}=1$ to $5 \%$, II $=6$ to $30 \%$, $\mathrm{III}=31$ to $70 \%, \mathrm{IV}=71$ to $100 \%)$. Values are means of average disease index from three lower and three upper leaves from three independent experiments. 
that the process of $S$-nitrosylation is mainly correlated to a reverse inhibition of the enzyme activity (Astier et al. 2011; Yun et al. 2011).

To assess whether the SNO level observed in primed plants as a consequence of inducer treatment may be changed after a further stress exposure, we measured the concentration of SNO after a challenge inoculation with $P$. infestans. In the control noninduced potato plants, the total content of SNO increased threefold at $72 \mathrm{~h}$ after $P$. infestans infection. In turn, leaf pretreatment with either BABA, GABA, or laminarin also showed an increase in the SNO level in the whole plants after the challenge inoculation, but it was significantly lower than in noninduced inoculated ones. The concentration of endogenous SNO was only higher in INA treated and then inoculated leaves when compared with noninduced infected leaves.

Identification of priming proteins that become specifically $S$-nitrosylated was not explored in our experimental approach, but it has been known for years that priming often depends on the sensitization of NPR1 (also known as NIM1 or SNI1) as a key regulator of induced disease resistance (Conrath et al. 2002; Zimmerli et al. 2000). Furthermore, it was well documented by Tada and associates (2008) that GSNO (as an NO donor) markedly facilitates the formation of inactive NPR1 oligomers directly through thiol $S$-nitrosylation, which finally suppresses $P R$ genes and abolishes plant resistance to the pathogen. Another example for regulatory function of NO is $S$-nitrosylation of salicylic acid-binding protein 3 (AtSABP3). $S$-nitrosylation of AtSABP3 reversibly suppresses both SAbinding activity and carbonic anhydrase (CA) (Wang et al. 2009). Inhibition of CA activity negatively modulates the plant immunity.

Emerging data suggest that SNO formation and turnover may constitute an important mechanism to control the expression of plant resistance to a pathogen. Using Arabidopsis mutants with an absent or increased $S$-nitrosoglutathione reductase (AtGSNOR1) activity, Feechan and associates (2005) revealed that an elevated SNO level was associated with an enhanced susceptibility to disease. Similarly, a higher content of SNO was observed in hypocotyls of a susceptible rather than a resistant sunflower cultivar infected with Plasmopara halstedii (Chaki et al. 2009). Evidently a precise and controlled SNO formation followed by reverse denitrosylation may promote effective defense responses of the plant. As far as induced resistance is concerned, many more research details would be needed to establish the role of SNO homeostasis in the stressimprint generation during a priming phenomenon in plants.

The ability of plants to perceive, store, and recall previous priming events is likely to prove useful for an amplified response to secondary stress. Recently published data suggest a tight correlation between histone modification patterns and gene priming for environmental and chemical signal storage for efficient stress responses (Conrath et al. 2011; Jaskiewicz et al. 2011). It is now recognized, in the neuronal physiology of animals, that chromatin remodeling factors and nuclear events are functionally regulated by NO (Nott and Riccio 2009). Among other changes, histone deacetylases could potentially be modulated through NO-dependent inhibition by $S$-nitrosylation (Watson and Riccio 2009). Much less is known about the mechanism of gene priming, and almost no data are available on the role of NO in the plant "memory" for SAR. Surprisingly, very recently, $S$-nitrosylation of both histone H2B putative and histone deacetylase 2C in PR nuclear proteins in Arabidopsis thaliana suspension cell cultures was found (C. Lindermayr, personal communication).

Our experimental model revealed that GSNO was able to activate the $H 2 B$ gene expression in potato leaves. The mRNA transcript for $\mathrm{H} 2 \mathrm{~B}$ histone was up-regulated early, in time agreement with a half-life of 6 to $7 \mathrm{~h}$ for GSNO in solution (Floryszak-Wieczorek et al. 2006). BABA facilitated the activation of histone $H 2 B$ gene expression in succeeding hours after the treatment. In contrast, the GABA-caused elevated level of the $H 2 B$ transcript was slightly reduced in time. For INA and laminarin, the level of analyzed transcripts remained unchanged after induction.

Recent data support a model of histone replacement and histone modifications that may create and regulate epigenetic changes for an enhanced reactivation upon a subsequent pathogen attack (Conrath 2011). Briefly speaking, the replacement of histone $\mathrm{H} 2 \mathrm{~A}$ by its variant H2A.Z seems to be crucial for the regulation of SA-responsive genes and transcriptional memory in SAR (March-Diaz et al. 2008; Van den Burg and Takken 2009). Histone modifications, such as $\mathrm{H} 3$ and $\mathrm{H} 4$ acetylation, and $\mathrm{H} 3 \mathrm{~K} 4$ methylation or di-methylation have also been linked to an epigenetic regulation (Jaskiewicz et al. 2011; Mosher et al. 2006). In turn, the role of histone H2B monoubiquitination (HUB1) in disease resistance was documented in Arabidopsis thaliana by Dhawan and associates (2009). The HUB1-mediated histone H2B modification was independent of histone $\mathrm{H} 3$ and DNA methylation, and its overexpression conferred resistance to necrotrophic pathogens. The above-mentioned authors did not exclude the possibility that HUB1-regulated histone ubiquitination could determine other chromatin modifications, which seems to be attributed to multiple regulatory events that depend on histone $\mathrm{H} 2 \mathrm{~B}$ monoubiquitination. Furthermore, it has been recently shown by Schouppe and associates (2011) that carbohydrate-dependent histone $\mathrm{H} 2 \mathrm{~B}$ modification is dramatically altered under stress conditions, with the effect of nucleocytoplasmic tobacco lectin-histone interaction playing a signaling role in response to biotic stress. Such detailed studies need to be continued to resolve the significance of chromatin modification for primed defense gene expression.

We next investigated whether applied inducers could trigger early signaling events that may be engaged in the resistance of potato to an oomycete pathogen, $P$. infestans. Our data revealed that potato plants exposed to chemical treatment showed differences in the level of acquired resistance among the studied agents. BABA treatment was the most effective in primed potato plants to mobilize faster and stronger responses after the challenge inoculation. GABA turned out to be less protective against the development of late blight symptoms. The application of laminarin enhanced mainly distal resistance against the oomycete pathogen. In contrast, INA at the concentration we used was unable to prime potato plants to an augmented capacity to trigger an effective activation of defense responses after contact with the challenging pathogen.

BABA has been found earlier to induce effective resistance of potato against $P$. infestans both in the greenhouse and in field conditions (Andreu et al. 2006; Cohen 2002; Li et al. 2009; Si-Ammour et al. 2003).

Summing up, there is evidence that potato plants are able to alter their metabolism in response to inducer treatment. It is assumed, for the mechanism suggested in this paper, that inducer used triggers NO-mediated changes involving reversible $S$-nitrosylated protein accumulation as one of the short-term stress imprint components, apart from epigenetic changes sensitized by NO. Generally, the level of SNO was significantly elevated at the time of inducer administration, while in contrast, SNO levels were strikingly reduced after challenge-inoculation when compared with noninduced potato plants. Based on the results obtained from BABA- and GABA-induced events, it should be stated that a rise in NO generation and a NO coding message in SNO storage at a relatively low threshold together with histone $H 2 B$ upregulation create a short-term 
imprint activation facilitating acquired resistance. In turn, laminarin-elicited strong NO upregulation together with an enhanced SNO pool altered the biochemical molecular pattern in the form of a less effective local recall, although still being fully protective in distal defense responses against $P$. infestans. Our results indicate that a precise control of synthesized NO in cooperation with reversible SNO storage and epigenetic modifications might play an important role in integrating and coordinating whole-potato responses in the priming phenomenon. Better knowledge on the molecular mechanisms of NO orchestration with other epigenetic changes involving plant stress imprint might help us in the future to apply new environmentally safe priming agents to improve potato protection against $P h y$ tophthora infestans and other pathogenic microorganisms.

\section{MATERIALS AND METHODS}

\section{Plant material.}

Sterile potato plants (Solanum tuberosum L.) of cv. Bintje susceptible to Phytophthora infestans, derived from in vitro tissue culture, were transferred to soil and were grown in a phytochamber with $16 \mathrm{~h}$ of light $\left(180 \mu \mathrm{mol} \cdot \mathrm{m}^{-2} \cdot \mathrm{s}^{-1}\right)$ at $18 \pm$ $2^{\circ} \mathrm{C}$ and $60 \%$ humidity up to the stage of ten leaves.

\section{Fungal culture.}

Phytophthora infestans race 1.3.4.7.10.11 as a virulent isolate of the pathogen was supplied by the Plant Breeding and Acclimatization Institute, Research Division at Młochów, Poland. The fungus was grown on a cereal-potato medium with an addition of dextrose. A zoospore suspension of $P$. infestans was prepared exactly as described by Floryszak-Wieczorek (2000).

\section{Plant priming.}

Three lower leaves were treated by spraying with the following solutions: $2 \mathrm{mM}$ BABA (Sigma Aldrich, St. Louis), $2 \mathrm{mM}$ GABA (Sigma Aldrich), or $0.15 \mathrm{mM}$ INA (Sigma Aldrich). Laminarin was extracted and purified from the marine brown algae Laminaria digitata, using Goëmar as Vacciplant product, used at a concentration of $90 \mathrm{mg}$ of pure laminarin in 1 liter of water. Control or noninduced plants were sprayed with water.

\section{Plant challenge-inoculation with $P$. infestans.}

Each potato plant was challenge-inoculated by spraying leaves with $5 \mathrm{ml}$ of a fungal zoospore suspension at a concentration of $1.0 \times 10^{5}$ per $1 \mathrm{ml}$ of water. For the purpose of disease assessment, inoculated plants were first kept for $12 \mathrm{~h}$ in the dark at $100 \%$ humidity and $18^{\circ} \mathrm{C}$. Plants were then moved to a growth chamber and were kept under controlled conditions.

\section{NO-donor treatment.}

The third compound leaves from the basis of intact plants were treated by spraying $200 \mu \mathrm{M}$ GSNO (Sigma Aldrich) and were then closed in an air-tight plastic chamber and exposed to light.

\section{NO detection and quantification.}

Electrochemical measurements were performed using a universal electrochemical analyzer, GSTAT 30 (EcoChemie, Utrecht, The Netherlands). NO generation in leaf tissue was monitored by differential pulse amperometry with a NO-selective needle-type electrode. The electrode was prepared by electropolymerizing a thin film of polyeugenol on a cleaned $\mathrm{Pt}$ needle. This was done by repetitive scanning of the electrode potential between -0.2 and $0.6 \mathrm{~V}$ in a $10 \mathrm{mM}$ solution of eugenol (Fluka, Buchs, Switzerland) in $0.1 \mathrm{M} \mathrm{NaOH}$ (Ciszewski and Milczarek 2003). The modified electrode was then condi- tioned by applying a constant potential of $0.9 \mathrm{~V}$ in a phosphate buffer ( $\mathrm{pH} 7.4)$, until a stable constant background current was reached. Electrochemical monitoring of NO generation in potato leaves after an inducer treatment was performed as described earlier by Floryszak-Wieczorek and associates (2007). The relationship between NO concentration and NO sensor current measurement is shown in Supplementary Figure 4.

\section{Quantification of total SNO.}

Total SNO content was determined by chemiluminescence using a Sievers Nitric Oxide Analyzer (NOA280i) (GE Analytical Instruments, Boulder, CO, U.S.A.), according to the procedure proposed by Valderrama and associates (2007) and Chaki and associates (2009) with minor modifications. The detection of SNO depends on the reductive decomposition of nitroso compounds by an iodine and triiodide mixture in the presence of copper. Gaseous NO released from the mercuryinduced decomposition of SNO is measured by gas-phase chemiluminescence at the PMT device. Fresh leaves $(0.5 \mathrm{~g})$ were homogenized in Tris- $\mathrm{HCl} 0.1 \mathrm{M}$ buffer, $\mathrm{pH} 7.5$ (1:4 $\mathrm{wt} / \mathrm{vol}$ ), containing $100 \mu \mathrm{M}$ diethylene triamine pentaacetic acid, $1 \mathrm{mM}$ EDTA, $1 \mathrm{mM}$ EGTA, $1 \mathrm{mM}$ phenylmethylsulfonyl fluoride, $0.1 \mathrm{mM}$ neocuproine, $3.5 \%$ (wt/vol) polyvinylpolypyrrolidone, $0.25 \%$ ( vol/vol) Triton X-100, and were centrifuged at $3,000 \times g$ for $10 \mathrm{~min}$. The supernatants were incubated with $10 \mathrm{mM}$ NEM ( $N$-ethylmaleimide) for $15 \mathrm{~min}$ at $4^{\circ} \mathrm{C}$. Subsequently, two aliquots were prepared for each sample. To remove nitrite, one aliquot was incubated for $15 \mathrm{~min}$ with $10 \mathrm{mM}$ sulphanilamide at $4^{\circ} \mathrm{C}$. To eliminate nitrite and decompose SNO, the next aliquot was treated with $10 \mathrm{mM}$ sulphanilamide and $7.3 \mathrm{mM} \mathrm{HgCl}_{2}$ for $15 \mathrm{~min}$ at $4^{\circ} \mathrm{C}$. The difference between detected signals obtained from these aliquots demonstrated the total SNO content. Due to SNO sensitivity to light, the whole procedure was performed under a red safety light.

\section{Determination of the transcript level of histone $\mathrm{H} 2 \mathrm{~B}$ gene by RT-PCR.}

Total RNA was extracted from $250 \mathrm{mg}$ of frozen leaves, using the TRI reagent (Sigma Aldrich) according to the manufacturer's instructions and were then treated with deoxyribonuclease I, amplification grade (Sigma Aldrich). Samples containing $1 \mu \mathrm{g}$ of RNA were used for RT with the RevertAid First-Strand cDNA synthesis kit (Thermo Scientific, Vilnius, Lithuania) and oligo- $(\mathrm{dT})_{18}$ primer, according to the manufacturer's procedure, in a final volume of $20 \mu \mathrm{l}$. For histone analysis the forward primer was used. Primers for $H 2 B$ were designed by Primer3 Output software and were based on available potato cDNA sequences (GI:82400145) found in the National Center for Biotechnology Information (GenBank). 18S $r R N A$ was used as a housekeeping gene (GI:511154). The following primers were used.

\section{H2B I: 5'-GGGAAGAAGCTACCAAAGGA-3'}

H2B II: 5'-ATCTAGAAGATTCCTGAGCCAGC-3' 18S rRNA I: 5'-GGGCATTCGTATTTCATAGTCAGAG-3' 18S rRNA II: 5'-CGGTTCTTGATTAATGAAAACATCCT-3'

Aliquots $(2 \mu \mathrm{l})$ of First-Strand cDNA $(1 \mu \mathrm{g} / \mu \mathrm{l})$ were amplified with the use of $2 \times$ Master Mix (Thermo Scientific), according to a previously described touch-down procedure (Sobkowiak and Deckert 2003, 2004). PCR reactions were performed as follows: one denaturation cycle of $3 \mathrm{~min}$ at $95^{\circ} \mathrm{C}, 35$ cycles of denaturation for $30 \mathrm{~s}$ at $95^{\circ} \mathrm{C}, 13$ cycles of primer annealing for $30 \mathrm{~s}$, at which temperature was decreased at each cycle by $1^{\circ} \mathrm{C}$ from $68^{\circ} \mathrm{C}$ to $55^{\circ} \mathrm{C}$, followed by 21 cycles of annealing at $55^{\circ} \mathrm{C}$, and elongation for $2 \mathrm{~min}$ at $72^{\circ} \mathrm{C}$. The final elongation was performed for $8 \mathrm{~min}$ at $72^{\circ} \mathrm{C}$. Amplified products were analyzed on $2 \%$ agarose gels and were stained with ethidium bromide. The amplified DNA was quantified by densitometry 
using a Multi Gauge V2.2 software (Fuji Film, Tokyo). All RTPCR tests were repeated three times, using three independent RNA samples.

\section{Assessment of disease index.}

The index of disease development on potato leaves at day 5 of $P$. infestans inoculation is based on a scale of 1 to 4 , which represented the percentage of leaf area covered by late blight symptoms ( $\mathrm{I}=1$ to $5 \%$; II $=6$ to $30 \%$; III $=31$ to $70 \%$; IV $=71$ to $100 \%)$. Values are means of index sporulation of three lower and upper leaves from three independent experiments.

\section{Statistical analysis.}

All experiments included three independent experiments carried out in at least three replications. For each experiment, means of the obtained values were calculated along with standard deviations. An analysis of variance was performed, and the least significant differences between means were determined using Tukey's test at the level of significance $\alpha=0.05$.

\section{ACKNOWLEDGMENTS}

This work was supported by a Grant of Polish Ministry of Science and Higher Education: N N303 340735

\section{LITERATURE CITED}

Abat, J. K., Mattoo, A. K., and Deswal, R. 2008. S-nitrosylated proteins of a medicinal CAM plant Kalanchoe pinnata-Ribulose-1,5-bisphosphate carboxylase/oxygenase activity targeted for inhibition. FEBS (Fed. Eur. Biochem. Soc.) J. 275:2862-2872.

Andreu, A. B., Guevara, M. G., Wolski, E. A., Daleo, G. R., and Caldiz, D. O. 2006. Enhancement of natural disease resistance in potatoes by chemicals. Pest Manag. Sci. 62:162-170.

Arasimowicz, M., and Floryszak-Wieczorek, J. 2007. Nitric oxide as a bioactive signalling molecule in plant stress responses. Plant Sci. 172:876-887.

Arasimowicz-Jelonek, M., Floryszak-Wieczorek, J., and Kubiś, J. 2009. Involvement of nitric oxide in water stress-induced responses of cucumber roots. Plant Sci. 177:682-690.

Astier, J., Rasul, S., Koen, E., Manzoor, H., Besson-Bard, A., Lamotte, O., Jeandroz, S., Durner, J., Lindermayr, C., and Wendehenne, D. 2011. S-nitrosylation: An emerging post-translational protein modification in plants. Plant Sci. 181:527-533.

Aziz, A., Poinssot, B., Daire, X., Adrian, M., Bézier, A., Lambert, B., Joubert, J.-M., and Pugin, A. 2003. Laminarin elicits defense responses in grapevine and induces protection against Botrytis cinerea and Plasmopara viticola. Mol. Plant-Microbe Interact. 16:1118-1128.

Baudouin, E. 2010. The language of nitric oxide signalling. Plant Biol. 13:233-242.

Beckers, G. J. M., Jaskiewicz, M., Liu, Y., Underwood, W. R., He, S. Y., Zhang, S., and Conrath, U. 2009. Mitogen-activated protein kinases 3 and 6 are required for full priming of stress responses in Arabidopsis thaliana. Plant Cell 21:944-953.

Benhar, M., Forrester, M. T., and Stamler, J. S. 2009. Protein denitrosylation: Enzymatic mechanisms and cellular functions. Nat. Rev. Mol. Cell Biol. 2009:721-732.

Bruce, T. J. A., Matthes, M. C., Napier, J. A., and Pickett, J. A. 2007. Stressful "memories" of plants: Evidence and possible mechanisms. Plant Sci. 173:603-608.

Chaki, M., Fernández-Ocaña, A. M., Valderrama, R., Carreras, A., Esteban, F. J., Luque, F., Gómez-Rodrígez, M. V., Begara-Morales, J. C., Corpas, F. J., and Barroso, J. B. 2009. Involvement of reactive nitrogen and oxygen species (RNS and ROS) in sunflower-mildew interaction. Plant Cell Physiol. 50:265-279.

Chester, K. S. 1933. The problem of acquired physiological immunity in plants. Q. Rev. Biol. 8:275-324.

Ciszewski, A., and Milczarek, G. 2003. Electrochemical detection of nitric oxide using polymer modified electrodes. Talanta 61:11-26.

Cohen, Y. R. 2002. $\beta$-aminobutyric acid-induced resistance against plant pathogens. Plant Dis. 86:448-457.

Cohen, Y., and Gisi, U. 1994. Systemic translocation of 14C-DL-3-aminobutyric acid in tomato plants in relation to induced resistance against Phytophthora infestans. Physiol. Mol. Plant Pathol. 45:441-456.

Cohen, Y., Reuveni, M., and Baider, A. 1999. Local and systemic activity of BABA (DL-3-aminobutyric acid) against Plasmopara viticola in grapevines. Eur. J. Plant Pathol. 105:351-361.

Conrath, U. 2009. Priming of induced plant defense responses. Pages 361395 in: Advances in Botanical Research. Academic Press. London.

Conrath, U. 2011. Molecular aspects of defence priming. Trends Plant Sci. 16:524-531.

Conrath, U., Pieterse, C. M. J., and Mauch-Mani, B. 2002. Priming in plant-pathogen interactions. Trends Plant Sci. 7:210-216.

Delledonne, M., Xia, Y., Dixon, R. A., and Lamb, C. 1998. Nitric oxide functions as a signal in plant disease resistance. Nature 394:585-588.

Dhawan, R., Luo, H., Foerster, A. M., Abuqamar, S., Du, H.-N., Briggs, S. D., Mittelsten Scheid, O., and Mengiste, T. 2009. HISTONE MONOUBIQUITINATION1 interacts with a subunit of the mediator complex and regulates defense against necrotrophic fungal pathogens in Arabidopsis. Plant Cell 21:1000-1019.

Dubreuil-Maurizi, C., Trouvelot, S., Frettinger, P., Pugin, A., Wendehenne, D., and Poinssot, B. 2010. $\beta$-aminobutyric acid primes an NADPH oxidase-dependent reactive oxygen species production during grapevinetriggered immunity. Mol. Plant-Microbe Interact. 23:1012-1021.

Durner, J., Wendehenne, D., and Klessig, D. F. 1998. Defense gene induction in tobacco by nitric oxide, cyclic GMP, and cyclic ADP-ribose. Proc. Natl. Acad. Sci. U.S.A. 95:10328-10333.

Feechan, A., Kwon, E., Yun, B.-W., Wang, Y., Pallas, J. A., and Loake, G. J. 2005. A central role for $S$-nitrosothiols in plant disease resistance. Proc. Natl. Acad. Sci. U.S.A. 102:8054-8059.

Floryszak-Wieczorek, J. 2000. Effect of Phytophthora infestans on the activity of oxygen scavenging enzymes in leaves of different potato genotypes. Phytopathol. Pol. 19:147-155.

Floryszak-Wieczorek, J., Milczarek, G., Arasimowicz, M., and Ciszewski, A. 2006. Do nitric oxide donors mimic endogenous NO-related response in plants? Planta 224:1363-1372.

Floryszak-Wieczorek, J., Arasimowicz, M., Milczarek, G., Jelen, H., and Jackowiak, H. 2007. Only an early nitric oxide burst and the following wave of secondary nitric oxide generation enhanced effective defence responses of pelargonium to a necrotrophic pathogen. New Phytol. 175:718-730

Hamiduzzaman, M. M., Jakab, G., Barnavon, L., Neuhaus, J.-M., and Mauch-Mani, B. 2005. $\beta$-aminobutyric acid-induced resistance against downy mildew in grapevine acts through the potentiation of callose formation and jasmonic acid signaling. Mol. Plant-Microbe Interact. 18:819-829.

Hammerschmidt, R. 1999. Induced disease resistance: How do induced plants stop pathogens? Physiol. Mol. Plant Pathol. 55:77-84.

Jakab, G., Cottier, V., Toquin, V., Rigoli, G., Zimmerli, L., Metraux, J.-P., and Mauch-Mani, B. 2001. $\beta$-aminobutyric acid-induced resistance in plants. Eur. J. Plant Pathol. 107:29-37.

Jakab, G., Ton, J., Flors, V., Zimmerli, L., Métraux, J.-P., and MauchMani, B. 2005. Enhancing Arabidopsis salt and drought stress tolerance by chemical priming for its abscisic acid responses. Plant Physiol. 139:267-274.

Jaskiewicz, M., Conrath, U., and Peterhänsel, C. 2011. Chromatin modification acts as a memory for systemic acquired resistance in the plant stress response. EMBO (Eur. Mol. Biol. Organ.) Rep. 12:50-55.

Kauss, H., Theisinger-Hinkel, E., Mindermann, R., and Conrath, U. 1992. Dichloroisonicotinic and salicylic acid, inducers of systemic acquired resistance, enhance fungal elicitor responses in parsley cells. Plant J. 2:655-660

Kessmann, H., Staub, T., Hofmann, C., Maetzke, T., Herzog, J., Ward, E., Uknes, S., and Ryals, J. 1994. Induction of systemic acquired disease resistance in plants by chemicals. Annu. Rev. Phytopathol. 32:439-459.

Klarzynski, O., Plesse, B., Joubert, J. M., Yvin, J. C., Kopp, M., Kloareg, B., and Fritig, B. 2000. Linear beta-1,3-glucans are elicitors of defense responses in tobacco. Plant Physiol. 124:1027-1038.

Kuć, J. 1982. Induced immunity to plant disease. Bioscience 32:854-860.

Li, Y., Tian, Z., Liu, J., and Xie, C. 2009. Comparative cDNA-AFLP analysis reveals that dl- $\beta$-amino-butyric acid induces resistance through early activation of the host-defense genes in potato. Physiol. Plant. 136:19-29.

Lindermayr, C., Sell, S., Muller, B., Leister, D., and Durner, J. 2010. Redox regulation of the NPR1-TGA1 system of Arabidopsis thaliana by nitric oxide. Plant 22:2894-2907.

March-Díaz, R., García-Domínguez, M., Lozano-Juste, J., León, J., Florencio, F. J., and Reyes, J. C. 2008. Histone H2A.Z and homologues of components of the SWR1 complex are required to control immunity in Arabidopsis. Plant J. 53:475-487.

Molinier, J., Ries, G., Zipfel, C., and Hohn, B. 2006. Transgeneration memory of stress in plants. Nature 442:1046-1049.

Moreau, M., Lindermayr, C., Durner, J., and Klessig, D. F. 2010. NO synthesis and signaling in plants-where do we stand? Physiol. Plant 138:372-383. 
Mosher, R. A., Durrant, W. E., Wang, D., Song, J., and Dong, X. 2006. A comprehensive structure-function analysis of Arabidopsis SNI1 defines essential regions and transcriptional repressor activity. Plant Cell $18: 1750-1765$.

Mou, Z., Fan, W., and Dong, X. 2003. Inducers of plant systemic acquired resistance regulate NPR1 function through redox changes. Cell 113:935-944.

Nakagami, H., Pitzschke, A., and Hirt, H. 2005. Emerging MAP kinase pathways in plant stress signalling. Trends Plant Sci. 10:339-346.

Nott, A., and Riccio, A. 2009. Nitric oxide-mediated epigenetic mechanisms in developing neurons. Cell Cycle 8:725-730.

Papavizas, G. C. 1964. Greenhouse control of Aphanomyces root rot of peas with aminobutyric acid and methylaspartic acid. Plant Dis. Rep. 48:537-541.

Papavizas, G. C., and Davey, C. B. 1963. Effect of amino compounds and related substances lacking sulfur on Aphanomyces root rot of peas. Phytopathology 53:116-122.

Prime-A-Plant Group: Conrath, U., Beckers, G. J. M., Flors, V., GarcíaAgustín, P., Jakab, G., Mauch, F., Newman, M.-A., Pieterse, C. M. J., Poinssot, B., Pozo, M. J., Pugin, A., Schaffrath, U., Ton, J., Wendehenne, D., Zimmerli, L., and Mauch-Mani, B. 2006. Priming: Getting ready for battle. Mol. Plant-Microbe Interact. 19:1062-1071.

Ren, D., Liu, Y., Yang, K.-Y., Han, L., Mao, G., Glazebrook, J., and Zhang, S. 2008. A fungal-responsive MAPK cascade regulates phytoalexin biosynthesis in Arabidopsis. Proc. Natl. Acad. Sci. U.S.A. 105:5638-5643.

Ross, A. F. 1961. Systemic acquired resistance induced by localized virus infections in plants. Virology 14:340-358.

Ryals, J. A., Neuenschwander, U. H., Willits, M. G., Molina, A., Steiner, H. Y., and Hunt, M. D. 1996. Systemic acquired resistance. Plant Cell 8:1809-1819.

Schouppe, D., Ghesquiere, B., Menschaert, G., De Vos, W. H., Bourque, S., Trooskens, G., Proost, P., Gevaert, K., and Van Damme, E. J. M. 2011. Interaction of the tobacco lectin with histone proteins. Plant Physiol. 155:1091-1102.

Shelp, B. J., Bown, A. W., and McLean, M. D. 1999. Metabolism and functions of gamma-aminobutyric acid. Trends Plant Sci. 4:446-452.

Si-Ammour, A., Mauch-Mani, B., and Mauch, F. 2003. Quantification of induced resistance against Phytophthora species expressing GFP as a vital marker: $\beta$-aminobutyric acid but not BTH protects potato and Arabidopsis from infection. Mol. Plant Pathol. 4:237-248.

Slaughter, A., Daniel, X., Flors, V., Luna, E., Hohn, B., and Mauch-Mani, B. 2012. Descendants of primed Arabidopsis plants exhibit resistance to biotic stress. Plant Physiol. 158:835-843.

Sobkowiak, R., and Deckert, J. 2003. Cadmium-induced changes in growth and cell cycle gene expression in suspension-culture cells of soybean. Plant Physiol. Biochem. 41:767-772.

Sobkowiak, R., and Deckert, J. 2004. The effect of cadmium on cell cycle control in suspension culture cells of soybean. Acta Physiol. Plant. 26:335-344

Spadaro, D., Yun, B.-W., Spoel, S. H., Chu, C., Wang, Y.-Q., and Loake, G. J. 2010. The redox switch: Dynamic regulation of protein function by cysteine modifications. Physiol. Plant. 138:360-371.

Tada, Y., Spoel, S. H., Pajerowska-Mukhtar, K., Mou, Z., Song, J., Wang, C., Zuo, J., and Dong, X. 2008. Plant immunity requires conformational changes of NPR1 via $S$-nitrosylation and thioredoxins. Science 321:952-956.
Ton, J., and Mauch-Mani, B. 2004. $\beta$-amino-butyric acid-induced resistance against necrotrophic pathogens is based on ABA-dependent priming for callose. Plant J. 38:119-130.

Ton, J., Jakab, G., Toquin, V., Flors, V., Iavicoli, A., Maeder, M. N., Métraux, J.-P., and Mauch-Mani, B. 2005. Dissecting the $\beta$-aminobutyric acid-induced priming phenomenon in Arabidopsis. Plant Cell 17:987-999.

Valderrama, R., Corpas, F. J., Carreras, A., Fernández-Ocaña, A., Chaki, M., Luque, F., Gómez-Rodríguez, M. V., Colmenero-Varea, P., del Río, L. A., and Barroso, J. B. 2007. Nitrosative stress in plants. FEBS (Fed Eur. Biochem. Soc.) Lett. 581:453-461.

Van den Burg, H. A., and Takken, F. L. W. 2009. Does chromatin remodeling mark systemic acquired resistance? Trends Plant Sci. 14:286-294.

Van den Burg, H. A., Tsitsigiannis, D. I., Rowland, O., Lo, J., Rallapalli, G., Maclean, D., Takken, F. L. W., and Jones, J. D. G. 2008. The F-box protein ACRE189/ACIF1 regulates cell death and defense responses activated during pathogen recognition in tobacco and tomato. Plant Cell 20:697-719.

Van Hulten, M., Pelser, M., van Loon, L. C., Pieterse, C. M. J., and Ton, J. 2006. Costs and benefits of priming for defense in Arabidopsis Proc. Natl. Acad. Sci. U.S.A. 103:5602-5607.

Van Loon, L. C. 1997. Induced resistance in plants and the role of pathogenesis-related proteins. Eur. J. Plant Pathol. 103:753-765.

Wang, Y.-Q., Feechan, A., Yun, B.-W., Shafiei, R., Hofmann, A., Taylor, P., Xue, P., Yang, F.-Q., Xie, Z.-S., Pallas, J. A., Chu, C.-C., and Loake, G. J. 2008. $S$-nitrosylation of AtSABP3 antagonizes the expression of plant immunity. J. Biol.Chem. 284:2131-2137.

Watson, P. M. D., and Riccio, A. 2009. Nitric oxide and histone deacetylases: A new relationship between old molecules. Commun. Integr. Biol. 2:1113.

Wendehenne, D., Durner, J., and Klessig, D. F. 2004. Nitric oxide: A new player in plant signalling and defence responses. Curr. Opin. Plant Biol. 7:449-455.

Yoshioka, H., Asai, S., Yoshioka, M., and Kobayashi, M. 2009. Molecular mechanisms of generation for nitric oxide and reactive oxygen species, and role of the radical burst in plant immunity. Mol. Cells 28:321-329.

Yun, B.-W., Feechan, A., Yin, M., Saidi, N. B. B., Le Bihan, T., Yu, M. Moore, J. W., Kang, J.-G., Kwon, E., Spoel, S. H., Pallas, J. A., and Loake, G. J. 2011. S-nitrosylation of NADPH oxidase regulates cell death in plant immunity. Nature 478:264-268.

Zeier, J., Delledonne, M., Mishina, T., Severi, E., Sonoda, M., and Lamb, C. 2004. Genetic elucidation of nitric oxide signaling in incompatible plant-pathogen interactions. Plant Physiol. 136:2875-2886.

Zhang, X. 2008. The epigenetic landscape of plants. Science 320:489-492.

Zimmerli, L., Jakab, G., Metraux, J. P., and Mauch-Mani, B. 2000. Potentiation of pathogen-specific defense mechanisms in Arabidopsis by $\beta$ aminobutyric acid. Proc. Natl. Acad. Sci. U.S.A. 97:12920-12925.

Zimmerli, L., Hou, B.-H., Tsai, C.-H., Jakab, G., Mauch-Mani, B., and Somerville, S. 2008. The xenobiotic $\beta$-aminobutyric acid enhances Arabidopsis thermotolerance. Plant J. 53:144-156.

\section{AUTHOR-RECOMMENDED INTERNET RESOURCES}

GenBank database: blast.ncbi.nlm.nih.gov/Blast.cgi

Primer3 program: biotools.umassmed.edu/bioapps/primer3_www.cgi 